\title{
Integration of a theoretical framework into your research study
}

\section{Roberta Heale, ${ }^{1}$ Helen Noble ${ }^{2}$}

10.1136/ebnurs-2019-103077

${ }^{1}$ Laurentian University, School of Nursing, Sudbury, Ontario, Canada

${ }^{2}$ Queens University Belfast, School of Nursing and Midwifery, Belfast, UK

\section{Correspondence to:}

Dr Roberta Heale, School of Nursing, Laurentian University, Ramsey Lake Road, Sudbury, P3E2C6, Canada; rheale@ laurentian.ca
Often the most difficult part of a research study is preparing the proposal based around a theoretical or philosophical framework. Graduate students '...express confusion, a lack of knowledge, and frustration with the challenge of choosing a theoretical framework and understanding how to apply it.. ${ }^{1}$ However, the importance in understanding and applying a theoretical framework in research cannot be overestimated.

The choice of a theoretical framework for a research study is often a reflection of the researcher's ontological (nature of being) and epistemological (theory of knowledge) perspective. We will not delve into these concepts, or personal philosophy in this article. Rather we will focus on how a theoretical framework can be integrated into research.

The theoretical framework is a blueprint for your research project $^{1}$ and serves several purposes. It informs the problem you have identified, the purpose and significance of your research demonstrating how your research fits with what is already known (relationship to existing theory and research). This provides a basis for your research questions, the literature review and the methodology and analysis that you choose. ${ }^{1}$ Evidence of your chosen theoretical framework should be visible in every aspect of your research and should demonstrate the contribution of this research to knowledge. ${ }^{2}$

\section{What is a theory?}

A theory is an explanation of a concept or an abstract idea of a phenomenon. An example of a theory is Bandura's middle range theory of self-efficacy, ${ }^{3}$ or the level of confidence one has in achieving a goal. Self-efficacy determines the coping behaviours that a person will exhibit when facing obstacles. Those who have high self-efficacy are likely to apply adequate effort leading to successful outcomes, while those with low self-efficacy are more likely to give up earlier and ultimately fail. Any research that is exploring concepts related to self-efficacy or the ability to manage difficult life situations might apply Bandura's theoretical framework to their study.

Often theories provide a foundation for the explanation of more complex phenomena, which are then situated within a theoretical framework. The purpose of a theoretical framework is to demonstrate the interaction and relationship among a set of concepts, which, as a whole, describe a more complicated phenomenon.

\section{Using a theoretical framework in a research study}

Example 1: the Big Five theoretical framework

The first example includes research which integrates the 'Big Five', a theoretical framework that includes concepts related to teamwork. These include team leadership, mutual performance monitoring, backup behaviour, adaptability and team orientation. ${ }^{4}$ In order to conduct research incorporating a theoretical framework, the concepts need to be defined according to a frame of reference. This provides a means to understand the theoretical framework as it relates to a specific context and provides a mechanism for measurement of the concepts.

In this example, the concepts of the Big Five were given a conceptual definition, that provided a broad meaning and then an operational definition, which was more concrete. ${ }^{4}$ From here, a survey was developed that reflected the operational definitions related to teamwork in nursing: the Nursing Teamwork Survey (NTS). ${ }^{5}$ In this case, the concepts used in the theoretical framework, the Big Five, were the used to develop a survey specific to teamwork in nursing.

The NTS was used in research of nurses at one hospital in northeastern Ontario. Survey questions were grouped into subscales for analysis, that reflected the concepts of the Big Five. ${ }^{6}$ For example, one finding of this study was that the nurses from the surgical unit rated the items in the subscale of 'team leadership' (one of the concepts in the Big Five) significantly lower than in the other units. The researchers looked back to the definition of this concept in the Big Five in their interpretation of the findings. Since the definition included a person(s) who has the leadership skills to facilitate teamwork among the nurses on the unit, the conclusion in this study was that the surgical unit lacked a mentor, or facilitator for teamwork. In this way, the theory of teamwork was presented through a set of concepts in a theoretical framework. The Theoretical Framework (TF)was the foundation for development of a survey related to a specific context, used to measure each of the concepts within the TF. Then, the analysis and results circled back to the concepts within the TF and provided a guide for the discussion and conclusions arising from the research.

\section{Example 2: the Health Decisions Model}

In another study which explored adherence to intravenous chemotherapy in African-American and Caucasian Women with early stage breast cancer, an adapted version of the Health Decisions Model (HDM) was used as the theoretical basis for the study. ${ }^{7}$ The HDM, a revised version of the Health Belief Model, incorporates some aspects of the Health Belief Model and factors relating to patient preferences. ${ }^{8}$ The HDM consists of six interrelated constituents that might predict how well a person adheres to a health decision. These include sociodemographic, social interaction, experience, knowledge, general and specific health beliefs and patient preferences, and are clearly defined. The HDM model was used to explore factors which might influence adherence to 
chemotherapy in women with breast cancer. Sociodemographic, social interaction, knowledge, personal experience and specific health beliefs were used as predictors of adherence to chemotherapy.

The findings were reported using the theoretical framework to discuss results. The study found that delay to treatment, health insurance, depression and symptom severity were predictors to starting chemotherapy which could potentially be adapted with clinical interventions. The findings from the study contribute to the existing body of literature related to cancer nursing.

\section{Example 3: the nursing role effectiveness model}

In this final example, research was conducted to determine the nursing processes that were associated with unexpected intensive care unit admissions. ${ }^{9}$ The framework was the Nursing Role Effectiveness Model. In this theoretical framework, the concepts within Donabedian's Quality Framework of Structure, Process and Outcome were each defined according to nursing practice. ${ }^{10}{ }^{11}$ Processes defined in the Nursing Role Effectiveness Model were used to identify the nursing process variables that were measured in the study.

\section{Conclusion}

A theoretical framework should be logically presented and represent the concepts, variables and relationships related to your research study, in order to clearly identify what will be examined, described or measured. It involves reading the literature and identifying a research question(s) while clearly defining and identifying the existing relationship between concepts and theories (related to your research questions[s] in the literature). You must then identify what you will examine or explore in relation to the concepts of the theoretical framework. Once you present your findings using the theoretical framework you will be able to articulate how your study relates to and may potentially advance your chosen theory and add to knowledge.
Funding The authors have not declared a specific grant for this research from any funding agency in the public, commercial or not-for-profit sectors.

Competing interests None declared.

Provenance and peer review Not commissioned; internally peer reviewed.

( $)$ Author(s) (or their employer(s)) 2019. No commercial re-use. See rights and permissions. Published by BMJ.

\section{References}

1. Grant C, Osanloo A. Understanding, selecting, and integrating a theoretical framework in dissertation research: Creating the blueprint for your "house". Administrative Issues Journal Education Practice and Research 2014;4.

2. Maxwell JA. Qualitative Research Design: An Interactive Approach. 2nd ed. Thousand Oaks, CA: Sage Publications, 2005.

3. Bandura A. Self-efficacy mechanism in human agency. Am Psychol 1982;37:122-47.

4. Salas E, Sims DE, Burke CS. Is there a "Big Five" in Teamwork? Small Group Res 2005;36:555-99.

5. Kalisch BJ, Lee H, Salas E. The development and testing of the nursing teamwork survey. Nurs Res 2010;59:42-50.

6. Rochon A, Heale R, Hunt E, Parent M, et al. Teamwork and Patient Care Teams in an Acute Care Hospital. Nurs Leadersh 2015;28:28-39.

7 Wells JS, Strickland OL, Dalton JA, et al. Adherence to intravenous chemotherapy in African American and white women with early-stage breast cancer. Cancer Nurs 2015;38:89-98.

8. Eraker SA, Kirscht JP, Becker MH. Understanding and improving patient compliance. Ann Intern Med 1984;100:258-68.

9. Martin J, Heale R, Lightfoot N, et al. Nursing processes related to unexpected ICU admissions. Diversity of Research in Health Journal 2018;2:50-65.

10. Doran D, Harrison MB, Laschinger H, et al. Relationship between nursing interventions and outcome achievement in acute care settings. Res Nurs Health 2006;29:61-70.

11. Irvine D, Sidani S, Hall LM. Linking outcomes to nurses' roles in health care. Nurs Econ 1998;16:58. 